\title{
sciendo
}

DOI 10.2478/sbe-2019-0010

SBE no. 14(1) 2019

\section{TALENT MANAGEMENT, EMPLOYEE RECOGNITION AND PERFORMANCE IN THE RESEARCH INSTITUTIONS}

\author{
MASRI Nadine EI \\ SULIMAN Abubakr \\ The British University in Dubai, UAE
}

\begin{abstract}
:
This paper aims to provide insight into talent management and employee recognition variables, in an effort to understand if these management practices are, in a way, implemented in the Research Institutions in Qatar. It also aims to examine the link of these two constructs to employee performance and to suggest a pathway to improve the current practices, if any, in order to enhance the work performance. The sample of the study consisted of 180 full time employees who were randomly selected and surveyed using an online personalized questionnaire. The results of the empirical research uncover that talent management and employee recognition can significantly affect the level of employee performance, as well contributing to the organizational success and positioning. This study also found that talent management and employee recognition are interrelated variables that affect employee performance. Talent Management and employee performance are seen as strategic tools to implement strategic objectives and to enhance employees and organization's performance. The study concludes with a set of recommendations for both practitioners and researchers working in Qatar and beyond. The results of the study emphasize the importance of managing employee recognition in shaping work performance. It seems to be individuals' need for recognition, esteem and social status continues to be a higher order need irrespective of time and context. This paper is the first paper in Qatar and the Middle East that examines the role of talent management and employee recognition in shaping employee performance in the context of research institutions.
\end{abstract}

Key words: Performance management (PM), performance appraisal (PA), Talent Management (TM), Employee Recognition (ER), Employee Performance (EP).

\section{Introduction}

Higher educational institutions are undergoing considerable changes and developments in managing the technical and human aspects of work. They are striving to create a healthy, conducive and familial workplace that motivates students, researchers, 
instructors and employees to feel retained, engaged, accepted and respected. Meanwhile, the continuously changing work environment and stakeholders' expectations put them under extreme pressures to keep current on these changes, developments and to improve work performance (Lumby and Foskett, 2016). Karlsson and Ryttberg (2016) studied the role of superiors and leaders in transforming universities into 'strategic actors'. They argued that there is an going awareness regarding improving performance in educational institutions, which "have consequences for life and work in academia. Who, in practice, is going to make sure that higher education institutions, in addition to providing high quality teaching and research, deliver on the new promises?" (p. 2).

This study looks into the talent management aspect of HR, which is important for the success work organizations, given its fundamental function in appointing staff with adequate skills and experiences to fulfill the organization's operational and strategic tasks. It will also examine the performance management aspect of $\mathrm{HR}$, an important activity that can add value when well designed, implemented and managed according to the unique context of the organization. In addition, this paper will also study the concept of employee recognition and its role in shaping the work outcomes. Research about the aforementioned concepts revealed that limited studies investigated the relationship between TM, ER and $\mathrm{PM}$ in the context of non-profit organization, including research institutions, as the focus was on private or public sectors such as banks, companies and ministries. However, the library search uncovers that no study has attempted to combine these three variables and tested how they affect each other, especially in the academic sector. Therefore, this paper aims to bridge this gap and contribute to previous research by investigates the links between TM, ER and PM in the Research Institutions in the State of Qatar

\section{Literature Review}

The notion of performance is highly important and of significant relevance for both the employee and the organization. Taking into consideration the importance of performance and the increasing interest for defining the concept and identifying best practices considerable research has been published (Mensah, 2015). Commonly, performance is seen as the association of the employee's ability to perform his tasks, meet the management expectation and reach the job targets (Mensah, et al., 2016). Mensash 2015 prefers to define performance as "the positive contribution of an employee to the performance of the organization". Empirical research revealed that performance is a multidimensional concept (Suliman, 2001) (Mensah, 2015) (Mensah, et al., 2016). The primary elements to evaluate performance are "work duties, work skills, desire to work, job performance (Quality, quantity), and readiness to innovate". One additional important dimension, "work enthusiasm," can be a key to reach high performance (Suliman, 2001). Moreover, an increase attention has been given to study behaviors taking into consideration its correlation with individual tasks performed. In recent years, negative work behavior that may harm the organization, and negatively affect the work and the organizational performance alike; as well as the work stress, captured the attention of both researchers and practitioners (Mensah, 2015). Stress has become an important subject, with many researchers focusing on identifying the causes and factors contributing to 
workplace stress. Several studies have connected work stress to undesirable individual performance and organizational ineffectiveness and thus entail the necessity to identify and develop strategies to manage and prevent work stress and its negative implications (Gbadamosi \& Ross, 2012).

On the other hand Employee engagement is the employee's commitment towards the organization goals. By all means, it is translated into the employee's discipline, personal initiative, adaptability, effort, and persistence in achieving the organizational objectives (Mone, et al., 2011). Trust and fairness in any organizational culture are the key to building and fostering an engaged environment between employees at different level. Creating such, an environment will help to build confidence and empower people to be more engaged and to serve the organisation's interest. Mone et al (2011) highlights the five majors PM activities, interrelated to employee engagement:

- Setting performance and development goals

- Providing ongoing feedback and recognition

- Managing employee development

- Conducting mid-year and year-end appraisals

- Building a climate of trust and empowerment

The earlier mentioned activities are the core of any PM adapted in any organization and enhance open discussion between the employee's and management. Setting goals is an important component of the PM, with empirical research suggesting that the level of engagement upsurges once goals are discussed and agreed upon collaboration between employees and managers (Mone, et al., 2011). Open discussion and communication about the organizational goals and strategic direction, are always key factors in helping members of the workforce to align their efforts with the organization's goals, and therefore increase effectiveness.

As mentioned throughout this study, PA and ongoing feedback to employees help in to increase their motivation and development. It is also worth mentioning that constructive and positive feedback, as well as recognition, can improve performance and increase engagement. According to Mone et al (2011), employee recognition can be seen as a form of positive feedback strengthening the employee's behavior, or highlighting the achievement of an objective or specific task. It also enhances the employee's satisfaction, motivation, and morale. In addition, recognition and reward can positively affect the organization's success, as it enhances the employee's performance. It is critical to mention that managers should know the best time and approach to provide feedback and recognition, in order to endorse high levels of engagement; otherwise, overdosed recognition may negatively affect the intrinsic motivation of (Mone, et al., 2011).

The year-end performance appraisal represents a critical exercise when it comes to PM, as it focuses on the employee's performance, in terms of behaviors, outcome, engagement, and upcoming work plan. Thus, it is important for the employee to be satisfied with the overall quality of the PA and its related discussions in order to see himself engaged and thus motivate him to increase engagement in the day-to-day work relations with colleagues and superiors. Moreover, it is important to mention that perception of "fairness" in any organizational processes, precisely performance evaluations, is highly important. It is critical to note that, the more transparent appraisals 
are and the more they encourage employee contributions, ensure an open discussion, include strong performance criteria and metrics, linked to promotion and compensation, and finally aligned with organizational strategic goals the more the they incline to be perceived as fair (Mone, et al., 2011). Research advocates that engaged employees not only pursue their work related objective but they also pay a good team work role, take responsibilities, and try their best to fully contribute to the organizational goals. Engagement has been found to have a positive impact on employee performance (Nazir \& Islam, 2017).

Similar to the Talent Management concept, employee recognition still lacks in a systematic theoretical definition (Brun \& Dugas, 2008). Employee Recognition is not just related to the psychological need of the individual, but should also be seen as an organizational and HR management tool. According to Brun \& Dugas (2008), recognition can be classified in four main categories: "personal recognition; recognition of results; recognition of work practice; and recognition of job dedication". Interaction is the basis of the recognition and can be categorized as "organizational interaction, vertical, horizontal, external and social". Several studies related to the organizational performance, productivity and efficiency, referred to motivation as an essential predictor of performance. Moreover, ER is an important element directly influencing employee motivation (Brun \& Dugas, 2008). Any individual is always in need of being recognized by his colleagues, family members, supervisors and customers, regardless of his job status or level. It is therefore unsurprising that, in previous studies recognition of efforts was ranked as the most important organizational practice (Brun \& Dugas, 2008). It is also worth mentioning that the lack of recognition represents a high risk factor contributing to the workplace distress (Brun \& Dugas, 2008).

Globalization, advanced technologies, and international competition contributed to the shift in the nature of work and professions; similarly, companies and businesses are impacted by these changes, which are reflected through the way work is performed, internal processes, restructuring, and leadership. These changes are an integral part of the organizational environment (Brun \& Dugas, 2008). Furthermore, and taking into consideration fast growing working environments and economic conditions, employees and managers are forced to respond to unexpected demands, which put them under tremendous pressure to deliver and sustain consistency. Having said that, training, engaging, and retaining talent turn to be a priority for the organization's management. The same author states that HR management practices and efforts to promote and ensure a good work environment; in particular engaging staff in the decision making process, encouraging teamwork, supporting training and development are classified as one of the organizational strategic objectives. Nowadays, there is a huge interest in promoting strong work ethic; moreover, it can be classified as trendy and fashionable. Employee Recognition (ER) as it deals with human dignity and social justice can definitely be classified as an ethical practice adopted by any organization. Moreover, recognizing an employee, regardless of his gender, background, culture, ethnicity goes hand in hand with emphasizing the notion of equality among people working in the same organization. Recognizing the work effort or achievement of an employee sends a positive signal about the management and the attention it pays to its workforce (Brun \& Dugas, 2008). Brun and 
Dugas, conclude that regardless of the job status, recognition represents a significant need for the employee. Moreover, ER is a key to build the employee identity, motivate him, and give importance to his daily tasks and a sense of contribution, as well to help employee development and well-being. Having an empowered, engaged, and motivated workforce raises the organization's performance and provides it with competitive advantage. As recognition can be monetary or non-monetary, it denotes a symbolic reward to the individual that can affect him emotionally (increasing his well-being, decreasing work stress), practically (motivation, development, performance), and financially.

According to Al Ariss, Casio, and Paauwe (2013) the practice of TM is driven by business and consulting organizations, while the academic field of TM is characterized by a lack of theoretical frameworks. Hence, they argued that there is no uniform understanding of the term's objectives and scope. However, the most common definition described TM as "activities and processes that involve a systematic identification of key positions that differentially contribute to the organization's sustainable competitive advantage, the development of a talent pool of high-potential and high-performing incumbents to fill these roles, and the development of a differentiated human resource architecture to facilitate filling these positions with competent incumbents, and to ensure their continued commitment to their organization" (Collings \& Mellahi, 2009) (Mensah, et al., 2016). Collings and Mellahi (2009) also noted that TM should start with identifying key positions and then developing a talent pool based on these positions. Furthermore, management should work in a systematic way to reduce/avoid employee turnover by efficiently assessing employees' motivation, commitment, and performance, making certain that these are aligned with the company`s mission and strategy. According to their in-depth literature review, Al Ariss et al. (2013) derived a conclusion stating that the best TM practices occur when an organization links TM to its own strategy and values, and does not imitate other organizations' practices. In addition, the TM initiative should be agreed upon at different management levels, especially when members may have varying perspectives on the organization's objectives and targeted performance.

Based on the above review of literature on TM, ER and EP the researchers developed the following three hypotheses which are represented in the conceptual model of the study shown in Figure (1) below:

$\mathrm{H} 1$ : There is a relationship between Talent Management practices and the level of Employee Performance.

H2: Employee Recognition affects the level of Employee Performance.

H3: Talent Management is related to Employee Recognition. 


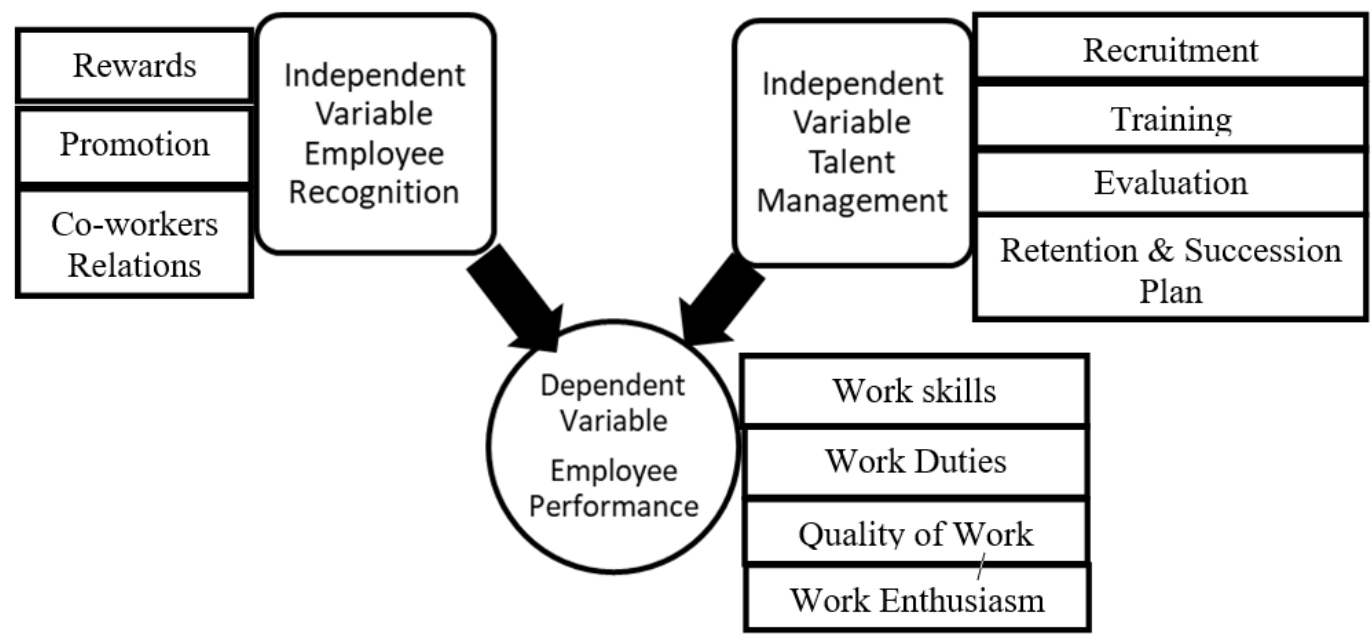

Figure 1: Conceptual Model of talent management, employee recognition and employee performance

\section{Methods}

\subsection{Research Design}

The objective of this study is to identify the relationship between the independent variables of talent management and employee recognition and the dependent variable employee performance. Empirical research indicates that researchers do not have definite control over the independent variables, thus their relationship can be more indicative than confirmed (Oladapo, 2014). One of the key dimensions of TM is the employee himself and how he evaluates management practices. Most of the research and experts in the field agree that talent can be a combination of an inborn gift and acquired abilities, and even though some people are born gifted with some talent, learning is considered as the essential factor contributing to the existent talent (Mensah, 2015). Furthermore, even if an employee doesn't demonstrate an innate talent, his performance can be improved through continuous training and development programs. Moreover, the literature reveals that the more an employee is engaged with the company's scope of work and his effort is recognized, the more he will be committed and loyal to his own work within the company, and therefore seek internal growth opportunities (Sidani \& Ariss, 2013).

To achieve the research objectives of this study, a quantitative method was used. Ten Research Institutes, operating in Qatar, were randomly selected to collaborate in this study. An online personalized questionnaire was distributed to the employees from diverse backgrounds and levels (bottom, middle and top).

\subsection{Sample and Data Collection}

A survey questionnaire was used to collect the primary data of the study on TM and ER on EP. Each individual was requested to respond spontaneously to the same set of questions. The questionnaire was circulated to 180 employees from various positions, 
educational backgrounds working at the selected research institution in Qatar. The Research Institutions were randomly selected; however, they all share a similar set of criteria governing the work environment such as size of the institutions, number of employees, research output and visibility. The study instrument consisted of 47 questions, organized into three sections:

A) Demographic Part: Gender, Educational Level, Age Group, Years worked in the current organization, Years worked in the position, Job Status (Manager, Employee, and Researcher), Nationality,

B) Technical Part (1): Questions pertaining to Talent Management and Employee Recognition, based on a Likert scale of 1 to 5 (1 Strongly Disagree- 5 Strongly Agree).

C) Technical Part (2): Questions pertaining to Employee Performance based on a Likert scale of 1 to 5 ( 1 Strongly Disagree- 5 Strongly Agree).

\subsection{Measures}

In order to measure the work performance variable, a four components scale, is adapted from Williams and Anderson (1991). The scale coverd four factors, namely: work skills, understanding work duties, quality of work and work enthusiasm on a five-point Likert scale (1_strongly disagree to 5_strongly agree).

To examine the Talent Management aspect of HR, 17 survey items were used covering four factors: Recruitment policy, Training and Development, Evaluation, and Retention and Succession Plan. The scale was modified and adopted from (Tiwari \& Shrivastava, 2013). Employee Recognition was measured based on 11 survey items covering three factors: Reward, Promotion, and Coworkers-Relations. The scale was modified and adopted from (Tiwari \& Shrivastava, 2013).

\section{Findings and Discussion}

The SPSS/PASW programme was used by the researchers to analyse the primary data collected from the online survey. Out of the 180 surveyed employees, 117 responded and completely filled the online survey, representing a response rate of 65 percent.

As table (1) exhibits, the sample consisted of $56(48 \%)$ females and $61(52 \%)$ males, of whom 3 had high school certificate, 3 had obtained a Diploma, 36 had obtained a Bachelor's degree, 42 had obtained their Master's degree and 33 had obtained their Doctoral degree. Most of the participants belonged to two age groups 25-35 (42\%) and 36$46(38 \%)$ and $12 \%$ were participants between the ages of $47-57$. Respondents who held management level positions represented $25 \%$ of the total sample, $30 \%$ were researchers and the remaining $45 \%$ were employees. In terms of years of experience spent in the same position $20 \%$ of the respondents had completed one year of work experience, $55 \%$ had completed 2 to 7 years, $15 \%$ had completed 8 to 13 years, $7 \%$ had completed 14 to 19 years and $3 \%$ had more than 20 years of work experience. As for the number of years spent in the current organization, $20 \%$ of the respondents had been associated with their current organization for 1 year or less, $57 \% 2$ to 7 years, $13 \%$ had spent 8 to 13 years, $5 \%$ spent between 14 to 19 and years and $5 \%$ spent 20 years or more. In terms of nationality, 
$9 \%$ of the respondents were Qatari while $91 \%$ were non-Qatari. Table 1 presents the demographical characteristics of the respondents in terms their gender, age distribution, educational level, nationality, job status, number of years worked in the position and at the organizational tenure.

The internal consistency of the TM, ER, and EP scales was tested by the Cronbach alpha. Alpha values greater than 0.7 are generally considered acceptable, values greater than 0.8 are considered good, and values greater than 0.9 are considered excellent. The reliability results are presented in the Table (2). As can be seen from this table, the alpha values for all three scales are close to or above 0.9 , indicating a high degree of internal consistency and scale reliability.

Table 1: Demographical Characteristic

\begin{tabular}{|c|c|c|c|}
\hline Demographic & Type & Frequency & Percent \\
\hline \multirow{2}{*}{ Gender } & Female & 56 & $47.9 \%$ \\
\hline & Male & 61 & $52.1 \%$ \\
\hline \multirow{5}{*}{ Education Level } & High School & 3 & $2.6 \%$ \\
\hline & Diploma & 3 & $2.6 \%$ \\
\hline & Bachelor Degree & 36 & $30.8 \%$ \\
\hline & Master's Degree & 42 & $35.9 \%$ \\
\hline & Doctoral Degree & 33 & $28.2 \%$ \\
\hline \multirow{5}{*}{ Age Group } & $18-25$ & 4 & $3.4 \%$ \\
\hline & $25-35$ & 49 & $41.9 \%$ \\
\hline & $36-46$ & 44 & $37.6 \%$ \\
\hline & $47-57$ & 14 & $12 \%$ \\
\hline & 58 or above & 6 & $5.1 \%$ \\
\hline \multirow{3}{*}{ Job Status } & Employee & 53 & $45.3 \%$ \\
\hline & Researcher & 35 & $29.9 \%$ \\
\hline & Manager & 29 & $24.8 \%$ \\
\hline \multirow{5}{*}{ Organizational Tenure } & One year or less & 23 & $19.7 \%$ \\
\hline & $2-7$ & 67 & $57.3 \%$ \\
\hline & $8-13$ & 15 & $12.8 \%$ \\
\hline & $14-19$ & 6 & $5.1 \%$ \\
\hline & 20 years or above & 6 & $5.1 \%$ \\
\hline \multirow{5}{*}{ Years worked at the same position } & One year or less & 23 & $19.7 \%$ \\
\hline & $2-7$ & 65 & $55.6 \%$ \\
\hline & $8-13$ & 17 & $14.5 \%$ \\
\hline & $14-19$ & 8 & $6.8 \%$ \\
\hline & 20 years or above & 4 & $3.4 \%$ \\
\hline \multirow{2}{*}{ Nationality } & Qatari & 11 & $9.4 \%$ \\
\hline & Non-Qatari & 106 & $90.6 \%$ \\
\hline
\end{tabular}


H1: There is a relationship between Talent Management Practices and the level of Employee Performance.

Pearson Correlation Coefficient and linear regression analysis - were used to examine the link between Talent Management Practices and Employee Recognition (Independent Variables) and the level of Employee Performance (Dependent Variable). The association between Talent Management and Employee Recognition was also examined using Pearson Correlation Coefficient.

Table 2: Findings of the Correlations and reliability tests*

\begin{tabular}{|l|l|l|l|l|}
\hline No & Variables & $\mathbf{1}$ & $\mathbf{2}$ & $\mathbf{3}$ \\
\hline $\mathbf{1}$ & Talent Management & $(.99)$ & & \\
\hline $\mathbf{2}$ & Employee Performance & .531 & $(.88)$ & \\
\hline $\mathbf{3}$ & Employee Recognition & .855 & .615 & $(.92)$ \\
\hline
\end{tabular}

${ }^{\star}$ All correlations are sig. at .01, reliabilities are in parenthesis.

Since the Pearson Correlation, value of 0.531 is greater than 0.5 and the $p$-value is significant at the 0.01 level (table 2), it can be concluded that a strong positive statistically significant relationship exists between Talent Management and Employee Performance.

Table 3: Regression test for EP to test global TM

\begin{tabular}{|l|l|l|l|l|l|l|l|}
\hline Independent Variables & $\beta$ & $\mathrm{t}$ & F-Value & F change & R2 & $\Delta$ R2 & Adjusted R2 \\
\hline TM.Global & $.531^{*}$ & 6.728 & $45.26^{*}$ & 45.26 & .282 & .282 & .276 \\
\hline Notes: ${ }^{*}$ p-value $<0.01 ;$ & \multicolumn{7}{|l|}{ Dependent Variable: Employee Performance } \\
\hline
\end{tabular}

In order to reinforce the result obtained and test the first hypothesis $\mathrm{H} 1$, a linear regression analysis was run for EP. EP was entered as a dependent variable while TM was entered as an independent variable. As Table (3) shows, the coefficient on the independent variable (TM) is positive and statistically significant. The adjusted R-squared value revealed that TM explains $27.6 \%$ change in EP. The F-value was significant (Fvalue=45.26, $p<0.01$ ), so the model was a good fit for the data. Hence, H1 is supported and the positive relationship between Talent Management Practices and of Employee Performance is established.

H2: Employee Recognition affects the level of Employee Performance.

As Table (2) reveals, the Pearson Correlation, value of 0.615 is greater than 0.5 and the p-value is significant at the 0.01 level. This indicates that there is a strong positive yet a statistically significant relationship between Employee Recognition and Employee Performance.

Table 4: Regression Analysis of EP and Global ER

\begin{tabular}{|l|l|l|l|l|l|l|l|}
\hline Independent Variables & $\beta$ & $\mathrm{t}$ & F-Value & F change & $\mathrm{R} 2$ & $\Delta \mathrm{R} 2$ & Adjusted R2 \\
\hline ER.Global & $.615^{*}$ & 8.365 & $69.969^{*}$ & 69.969 & .378 & .378 & .373 \\
\hline Notes: ${ }^{*} \mathrm{p}$-value $<0.01 ;$ & \multicolumn{7}{|c|}{ Dependent Variable: Employee Performance } \\
\hline
\end{tabular}


In the linear regression analysis ER was entered as independent at this equation (table 4). The findings showed that ER is significantly explaining the variance in Employee Performance with the F-value $=69.969(p<0.01)$ and the $t=8.365$. The adjusted R-squared shows that ER explains $37.3 \%$ change in the employee performance. The regression analysis results further support the previous test results, thus we can conclude that relationship between Employee Recognition and Employee Performance is established and $\mathrm{H} 2$ is supported.

H3: Talent Management associates with Employee Recognition.

Since the Pearson Correlation, value of 0.855 is greater than 0.5 and the p-value is significant at the 0.01 level (table 2), it can be concluded that a strong positive and statistically significant relationship exists between Talent Management and Employee Recognition. This suggests that one of the independent variables may have a stronger association with Employee Performance and may even be capturing part of the association of the other independent variable.

Table 5: Regression Analysis of EP, Global ER and Global TM

\begin{tabular}{|l|l|l|l|l|l|l|}
\hline Independent Variables & $\beta$ & F-Value & F change & R2 & $\Delta$ R2 & Adjusted R2 \\
\hline Step 1: Control Variables & & 45.26 & 45.26 & .282 & .282 & .276 \\
\hline TM.Global & $.531^{*}$ & & & & & \\
\hline & & & & & & \\
\hline Step 2: ER Global & $.597^{*}$ & 34.698 & 17.601 & .378 & .096 & .367 \\
\hline \multicolumn{1}{|c|}{ TM Global } & .021 & \multicolumn{7}{|l|}{ Dependent Variable: Employee Performance } \\
\hline Notes: ${ }^{*}$ p-value $<0.01$ & \multicolumn{7}{|l|}{} \\
\hline
\end{tabular}

A multivariate linear regression analysis was run, in an effort to test whether one of the independent variables is responsible for most of the relationship observed between ER, TM and EP. In the first step of the regression, EP was entered as a dependent variable while the control variable TM entered as independent variable. In the second step, both TM and ER were entered as independent variables. As Table 5 shows, the beta value for ER was the highest, meaning that ER made the greatest contribution to this model. The p-values was less than 0.01 for ER, which means that this variable made statistically significant contributions to the model. However, coefficient on TM decreased to 0.021 and was no longer statistically significant. This suggests that the EP is mostly a function of ER. The change in R-squared shows that adding ER in the next step increases the prediction capacity of the model by $9.6 \%$, which is a significant percentage. The F-value was significant ( F-value=34.698, $p<0.01$ ), so the model was a good fit for the data. The regression analysis results further indicate that there is a relationship between the two independent variables TM and ER; however, ER is the most significant factor affecting the Employee Performance.

The findings of this study evidently indicate that there is a positive relationship between Talent Management and Employee Performance. This findings is aligned with previous studies which stated that Talent Management practices are very important in developing employee skills, increase its performance and retain them, (Mensah, et al., 
2016) stated that adopting an effective TM practice increases employee performance same as the findings of (Sidani \& Ariss, 2013). The study also shows that that a strong yet positive relationship exists between Employee Recognition and Employee Performance. The aforementioned result is consistent with previous empirical researches which stated that recognition and reward can positively affect the organization's success, as it enhances the employee's performance (Mone, et al., 2011). Moreover, it is aligned to (Brun \& Dugas, 2008) study which revealed that recognition (monetary or non-monetary) denotes a symbolic reward to the individual that can affect him emotionally (increasing his well-being, decreasing work stress), practically (motivation, development and performance), and also financially. However, and based on the statistical results of this study Employee Recognition has more impact and can strongly affect the employee performance. Hence, this finding is consistent with previous empirical research written by (Brun \& Dugas, 2008) which stressed that adopting a recognition system is considered as an ethical practice that enhance the employee performance. It also contributes to promote a healthy work environment, decrease the work stress, increase the employee engagement and loyalty and ensure creating a culture of trust and fairness between coworkers and the management, which also ranked as the most important factor affecting the employee performance (Brun \& Dugas, 2008).

Moreover, this study tried to investigate if TM and ER were correlated. The findings revealed that there is a strong association between the two independent variables TM and ER, which shows that these two variables are interrelated and are very important aspects of the HR management that can affect the employee performance in specific, and the performance of any institution in general. Moreover, it indicates that ER is a critical factor that affects the EP, and which is more significant than TM in terms of impact. This finding is aligned with (Haghparast, et al., 2012) study that stated, reward or in other term recognition is a critical factor that affects the TM system adopted by any organization, as well as EP.

This paper also revealed that regardless of the employee characteristics in terms of demographical classification, TM and ER strongly affects the employee performance at different age and at different work and educational level, and this is compatible with (Brun \& Dugas, 2008), who stated that any employee should be recognized regardless of his job status, age, ethnicity... It is also consistent with (Ali \& Shedlock, 2010), as well as (Sidani \& Ariss, 2013) who based their studies on the case of GCC and region, and stated that introducing different appraisal system and different compensation packages based on specific individual characteristic may contribute to the work distress and increase the employee perception of injustice and inequity.

\section{Conclusions}

This study explored the links between talent management, employee recognition and employee performance in the research institutions in the State of Qatar. The research findings uncover that there is a strong positive significant relationship between talent management and employee performance on one hand and a significant positive 
relationship between on the other hand. However, employee recognition was found to be more important in predicting employee performance than talent management.

Creating a Talent Management system that best fit the organizational structure is essential for any organization, as it affects the employees' level of engagement, commitment and most importantly their performance, which is crucial to ensure the continuity and good positioning of any organization. It is also worth to mention that the TM system should always be aligned with the organizational strategy and its objectives, and never be imported. Similar to the concept of TM, Employee Recognition is an important management practice that strongly affects the employee performance and increases his/her willingness to take more responsibility, as well promotes an ethical practice that promote a healthy work environment. Moreover, such practices may shape employees' behavior and improve their performance, which will positively affect the Performance Management system. Recognizing the importance of human capital in any institution sends a clear signal that the top management values the PM and TM process.

This study has found that Talent Management and Employee Recognition have a significant and positive impact on Employee Performance, which is consistent with some previous studies and indicates that Talent Management and Employee Recognition have a strong association. The results of the study further affirm that non-profit sector in general, and Research Institutions in specific don't differ from the public sector and the profitoriented businesses, in terms of the employee's perception of TM, PM and ER adopted by the institution, and how such HRM practices can impact the employee performance.

According to the information collected through this research and the results of the study, it is important for the research institutions, operating in the state of Qatar to look into the Talent Management System that they are currently adopting to strive ways of improvement if needed as it directly affects the performance of its staff (administrative and researchers). As well, it would be also beneficial to look into the Performance Appraisal approach, to make sure it is a constructive exercise between the employee and the Manager, specifically that it directly affects the Employee Recognition, a key variable that impacts the employee performance. Additionally, the management should work on creating an ethical work environment by promoting a culture of trust and fairness through an ongoing, open discussion between colleagues and managers in order to reduce the work distress increase the employee engagement that can enhance the overall employee performance.

The study results provide insights into the management practices in a handful number of Research Institution operating in Qatar. It shows that TM and ER are adopted as part of the HRM system, and that they can affect the employee performance. These findings can be a starting point for future in- depth research into the creation of the appropriate systems that best fit a Research Institution, and the effectiveness of their implementation in order to enhance the employee performance. Moreover, the results highlight a strong association between Talent Management and Employee Recognition, and its impact on Employee Performance, from the employees' perspective only. Therefore, it would be beneficial to look into these HR practices from the HR professionals and Managers involved in the Performance Appraisal exercise. This finding can also be a starting point for future in-depth research to help provide a comparison between the 
employee versus manager perception of talent management, performance management and employee recognition in an effort to select the most effective ways of implementing these HR Practices in Qatar and the Region. Future research in this field, may also attempt to adopt the Results Method of performance appraisal rather than Traits or Behavioral methods of appraisal used in this study. Though they may be difficult to obtain sometimes, compared to self-ratings and manager-ratings, measures like published research papers, number of sections/students taught, hours worked or number of customers served may better assessed sample performance.

\section{Limitations}

This study was designed and limited to investigate the relationship and impact of talent management and employee recognition on employee performance of researchers and staff working in ten Research Institutions operating in the State of Qatar. Hence, limiting the study to one country in the Gulf region, doesn't give the researchers the opportunity to create a constructive comparison that would help underlining different practices between Research Institutions working in similar contexts, i.e. the GCC, MENA and Middle East in general. Additionally, the survey was limited in terms of presenting the employee's perspective only; which is not bias-free. As for employee performance, for example, the researchers were neither able to get access to the real performance appraisal outcomes for the coopted sample, nor allowed to measure employee performance using a more objective measure such as number of students counselled and number of research conducted.

\section{References}

Ali, A. J. \& Shedlock, F. E., (2010). Talent Management In The Arab World. In: R. A. Oglesby, I. H. Paul LeBlanc \& M. G. Adams, eds. Global Business Perpectives. 1 ed. s.I.:The International Academy of Business Disciplines: 350-354.

Brun, J. P. \& Dugas, N., (2008). An analysis of employee recognition: Perspectives on human resources practices. The International Journal of Human Resource Management, 19(4): 716-730.

Budworth, M. H., p.Latham, G. \& Manroop, L., (2014). Looking Forward to Performance Improvement: A field Test of The Feedforward Interview For The Performance Management. Human Resources Management, 54(1): 45-54.

Chavan, M., (2009). The balanced scorecard: a new challenge. Journal of Management Development, 28(5): 393-406.

Collings, D. G. \& Mellahi, K., (2009). Strategic talent management: A review andresearch agenda.. Human Resource Management Review, 19(4), p. 304-313.

Foldger, R., Konovsky, M. A. \& Cropanzano, R., (1992). A Due process metaphor for performance appraisal. In: B. M. Staw \& L. Cummings, eds. Research in Organizational Behavior. s.I.:JAI PRESS INC. pp. 129-77.

Gbadamosi, G. \& Ross, C., (2012). Perceived Stress and Performance Appraisal Discomfort: The Moderating Effects of Core Self-Evaluations and Gender. Public Personnel Management, 41(4): 637-659.

Haghparast, S., mehrdad, m. \& hasan, m., (2012). Relationship between talent management and organizational success.. International Research Journal of Applied and Basic Sciences, 3(12): 2424-2430. 
III, V. Y. \& Ste-Onge, S., (2012). Performance management effectiveness: practices or context?. The International Journal of Human Resource Management, 23(6): 1158-1175.

Jr, P. W. T. \& McNall, L., (2010). Justice perceptions of performance appraisal practices. Journal of Managerial Psycology, 25(3): 201-228.

Langevin, P. \& Mendoza, C., (2013). How can management control system fairness reduce managers' unethical behaviours?. European Management Journal, 31(3): 209-222.

Linna, A. et al., (2012). Can usfulness of performance appraisal interviews change organizational justice perceptions?A 4-year longitudinal study among public sector employees.. International Journal of Human Resource Management, 23(7): 1360-1375.

Lumby, J. and Foskett, N. (2016). Internationalization and culture in higher education. Educational Management Administration \& Leadership, 44(1): 95-111.

Karlsson, S. \& Ryttberg, M. (2016). Those who walk the talk: the role of administrative professionals in transforming universities into strategic actors, Nordic Journal of Studies in Educational Policy, 2016:2-3, 31537, DOI: 10.3402/nstep.v2.31537

Mensah, J. K., (2015). A coalesced framework of talent management and employee performance: For further research and practice. International Journal of Productivity and Performance Management, 64(4): 544-566.

Mensah, J. K., Bawole, J. N. \& Wedchayanon, N., (2016). Unlocking the "black box" in the talent management employee performance: relationship: evidence from Ghana. Management Research Review, 39(12): 1546-1566.

Mone, E. et al., (2011). Performance Management at the Wheel: Driving Employee Engagement in Organizations. Journal of Business and Psychology, 26(2): 205-212.

Nazir, O. \& Islam, J. U., (2017). Enhancing organizational commitment and employee performance through:employee engagement: An empirical check. South Asian Journal of Business, 6(1): 98114.

Oladapo, V., (2014). The Impact of Talent Management on Retention. Journal of Business Studies Quarterly, 5(3): 19-36.

Schuler, R. S., Jackson, S. E. \& Ibraiz, T., (2011). Global talent management and global talent challenges: Strategic opportunities for IHRM. Journal of World Business, 46(4): 506-516.

Scullen, S. E. \& Mount, M. K., (2000). Understanding latent structure of job performance ratings. Journal of Applied Psychology, 85(6): 956-970.

Sidani, Y. \& Ariss, A. A., (2013). Institutional and corporate drivers of global talent management: Evidence from the Arab Gulf Region. Journal of World Business: 215-224.

Singh, A., Jones, D. B. \& Hall, N., (2012). Talent Management: A Research Based Case Study in the GCC Region. International Journal of Business and Management, 7(24): 94-107.

Tiwari, U. \& Shrivastava, D., (2013). Strategies And Practices Of Talent Management And Their Impact On Employee Retention And Effectiveness. The International Journal Of Management, 2(4): 1-10.

Weijden, I., Teelken, C., de Boer, M. and Drost, M. (2016). Career satisfaction of postdoctoral researchers in relation to their expectations for the future. Higher Education, 72(1): 25-40.|

Williams, L. and Anderson, S. (1991). Job Satisfaction and Organizational Commitment as Predictors of Organizational Citizenship and In-Role Behaviors. Journal of Management. 17(3). pp. 601 - 617.

Wood, R. E. \& Marshall, V., (2008). Accuracy and effectiveness in appraisal outcomes: the influence of self-efficacy, personal factors and organisational variables. Human Resource Management Journal, 18(3): 295-313.

Youngcourt, S. S., Leiva, P. I. \& Jones, R. G., (2007). Perceived Purpose of Performance Appraisal: Correlates of Individual-and Position-Focused Purposes on Attitudinal Outcomes.. Human Resource Developement Quarterly, 18(3): 315-343. 